\title{
A review on optimal location of distributed generation techniques in electrical network
}

\begin{abstract}
To increase the maximum possible benefits of technical, economic and environmental aspects, the optimal sizing and sitting of distributed generation in distribution system has always been challenging for customers as well as to utilities. The objective of optimum sitting of distributed generation in a distribution system is to reach suitable operation of such systems with minimization losses of the systems, voltage profile improvement, enhanced system load ability, stability and reliability. In this paper, a review of techniques for optimum sitting of distributed generation units in distribution systems and study their effects on customers and utilities are presented. Also, a comparison was done between methods for optimum location of distributed generation in distribution systems.
\end{abstract}

Keyword: Distributed generation; Smart grid; Optimal location; Distribution networks; Minimization losses 